\title{
Effect of emphasis spread on coronal stop articulation in Qatari Arabic
}

\author{
Vladimir Kulikov, Fatemeh Mohsenzadeh \& Rawand M. Syam
}

\begin{abstract}
Emphasis (contrastive uvularisation) in Arabic spreads from an emphatic consonant to neighboring segments (Davis 1995). The effect of emphasis spread on a consonant is manifested as lowering of its spectral mean (Jongman et al. 2011). Although stop consonants reveal a strong effect of emphasis, it is not known how emphasis spread affects other acoustic properties of stops, e.g. voice onset time (VOT). Previous studies (Kulikov 2018) showed that VOT and emphasis are linked in speech production: plain /t/ in Gulf Arabic is aspirated; emphatic /t / has short-lag VOT. Phonological theory predicts that plain /t/ should become more emphatic in emphatic context, which might reduce stop VOT as well. The current study investigates the effect of emphasis spread on VOT in word-initial coronal stops in Qatari Arabic. The stimuli, produced by sixteen native speakers of Qatari Arabic, contained target plain and emphatic stops /t/, /ț/ followed by short or long low vowel, and plain coronal obstruents /t, s, ð/ or their emphatic counterparts /ț, ș, ọ/. The acoustic analysis included measurements of VOT and spectral mean of burst in the stop, and F1, F2, F3 frequencies at the vowel beginning, middle and end. The results showed that final emphatic obstruent triggered emphasis spread across the syllable. The effect of emphasis on the vowel was stronger next to the emphatic obstruent $(p<$ $.01)$. Spectral mean of burst in plain /t/ was lower in the emphatic context $(D=276$ $\mathrm{Hz}, p=.05)$. VOT, however, was not affected by emphasis spread. Plain $/ \mathrm{t} / \mathrm{had}$ longlag VOT averaging $52 \mathrm{~ms}$; emphatic/ț/ had short-lag VOT averaging $17 \mathrm{~ms}$. These values were not different in emphatic context $(p=.743)$. The findings demonstrate that emphasis spread within a syllable affects only spectral characteristics of a coronal stop. Emphaticness of plain / $t /$ did not affect its VOT and did not result in complete transformation of the stop category.
\end{abstract}

Keywords. VOT; emphasis; emphatic stop; Arabic; Qatari dialect

1. Introduction. Emphasis, or uvularization/pharyngealization, is a contrastive feature in Arabic that distinguishes a group of coronal obstruents with a secondary constriction in the posterior area of the vocal tract. Thus, in Standard Arabic and many spoken dialects of Arabic plain (nonemphatic) dental/alveolar obstruents /t, d, s, ð/ have four emphatic counterparts /ț, ḍ, ș, ọ/. In other spoken dialects, e.g. Gulf Arabic, only three coronal obstruents /t, s, ð/ have emphatic counterparts /t, $\mathbf{s}$, ọ/ as a result of merger of the voiced emphatic stop with a voiced emphatic fricative (Feghali 2008). Previous studies of emphasis (Ghazeli 1977, McCarthy 1994, Yeou 1997, Zawaydeh 1999, Zawaydeh \& de Jong 2002) have shown that retraction of the tongue is crucial to create a posterior constriction, although the precise location of the posterior constriction in the pharyngeal or uvular areas is still a matter of debate.

Emphatic articulation in obstruents affects preceding and following segments resulting in socalled emphasis spread (McCarthy 1994, Davis 1995, Watson 1999). Emphasis spread in Arabic dialects differs both in the direction and scope of coarticulatory effect. Phonological analysis of emphasis spread typically represents emphatic coarticulation as sharing the [RTR] feature (McCarthy 1994, Davis 1995). While in some dialects, such as southern Palestinian (Watson 1999) or southern Saudi Arabian (Younes 1993) the spread is rightward and it predominantly 
affects only the following vowel, in other dialects, e.g. northern Palestinian Arabic (Watson 1999), Lybian (AlGryani 2014), and urban Jordanian Arabic (Jongman et al. 2011), leftward spread affects all segments preceding the emphatic consonant but rightward spread affects only the following vowel. Some dialects, e.g. Qatari Arabic (Bukshaisha 1985 in Watson 1999), Cairene Arabic (Watson 2002) demonstrate emphasis spread across the entire word. Leftward spread was shown to have a stronger effect and to be less restrictive than rightward spread. Even in the dialects with both types of emphasis spread, leftward spread typically invariably affects all segments (Zawaydeh \& de Jong 2002), but rightward spread can be blocked by some categories of segments, e.g. high segments /i, j, J/, at least in some Arabic dialects (Davis 1995).

Sharing the emphatic gesture with the adjacent vowel causes subsequent lowering of F2 and raising of $\mathrm{F} 1$. In dialects where emphasis is realized as uvularization, tongue movement toward the uvula also causes F3 raising on the adjacent vowel (Jongman, Herd, Al-Masri, Sereno \& Combest 2011). In addition, the proximity between F1 and F2 was also shown to be characteristic of emphasis (Yeou 1997). This index is particularly helpful when locus of the secondary constriction is above the pharyngeal area. F1 raising in these cases can be inconsistent or may not reach significance level (Kulikov 2019). In consonants, the typical acoustic correlate of emphasis is lowering of the spectral mean (Jongman et al. 2011). Most acoustic studies of Arabic emphasis, however, focused only on changes in spectral characteristics of sounds affected by emphasis spread. Very few studies investigated effects of emphasis spread on temporal acoustic properties of emphatic consonants, e.g. Voice Onset Time (VOT) in stops.

Although VOT is typically assumed to be an acoustic correlate to stop voicing (Lisker \& Abramson 1964), in Arabic it also intersects with emphasis. The phonological voicing contrast in Modern Standard Arabic is described in very general terms as a contrast between "voiced" stops (e.g. $b, d$ ) and "voiceless" stops (e.g. $t, k$ ) (Feghali 2008, Watson 2002). Phonetic implementation of the contrast, however, varies from dialect to dialect. In some dialects, e.g. Lebanese Arabic (Yeni-Komshian, Caramazza \& Preston 1977, Khattab 2000), the contrast is between voiceless unaspirated stops and stops with lead voice. Other dialects, e.g. Jordanian Arabic (Mitleb 2009) contrast voiceless aspirated and voiceless unaspirated categories. Some Gulf Arabic dialects, e.g. Qatari Arabic (Kulikov 2019), have a contrast between voiceless aspirated stops and stops with lead voice.

Previous acoustic studies (AlDahri 2013, Mitleb 2001, Khattab et al. 2006) showed that VOT is consistently shorter in emphatic stops than in plain stops. AlDahri (2013) in his study of emphaticness in Saudi Arabic reports that VOT in emphatic/ț $\mathrm{d} /$ is almost twice as short as in plain /t, d/. Kulikov (2019) also reports shorter VOT in emphatic stops in the Arabic dialect of Qatar. The two categories of stops in this dialect fall into two distinct VOT categories: plain coronal stop /t/ is voiceless aspirated, whereas emphatic stop /t / is voiceless unaspirated. Due to absence of the contrast in voiced coronal stops VOT in this dialect has become an important cue to distinguish the phonological contrast between plain /t/ and emphatic /t $/$.

The link between VOT and emphasis seems to be reciprocal: a change in one category might trigger a change in another category. Khattab, Al-Tamimi and Heselwood (2006) examined an on-going loss of emphasis in the speech of female speakers of the Jordanian Arabic. The results showed that lower degree of emphasis in emphatic/t / correlated with longer VOT values in those stops. Therefore, it is not unreasonable to assume that similar link might be found in the phonological process of emphasis spread. When a plain stop occurs at the emphatic environment, emphasis spread might not only change its spectral characteristics but also reduce its VOT value. 
Such a change, if detected, might indicate that there is strong requirement to reduce duration of VOT as the tongue back is retracted in the vocal tract.

Research on VOT in various languages also suggests that VOT is sensitive to vowel articulation in general. Retraction of the tongue back reduces VOT in emphatic stops, but more front position of the tongue produces the opposite effect. Stops have been shown to have longer VOT before front vowels in English (Klatt 1975, Nearey \& Rochet 1994) or French (YeniKomshian, Caramazza \& Preston 1977), among other languages. In Russian, a language with contrastive palatalization in consonants, palatalized coronal / $t$ / has consistently longer VOT than non-palatalized (or velarized) /t/. It is of note, that non-palatalized, or velarized / $/$ in Russian is typically realized as a voiceless unaspirated stop with VOT averaging at $20 \mathrm{~ms}$ (Ringen \& Kulikov 2011). But palatalization of /t/ before /i/ considerably increases its VOT $(M=47 \mathrm{~ms})$ (Kochetov 2006). Moreover, longer VOT before /i/ often leads to affrication in Russian, so that the stop phoneme /t/ is optionally realized as a dental affricate [ts] in casual speech (Knyazev 2016).

These examples suggest that relation between front/back tongue position and VOT can have two types of outcome: (1) it can be a gradient phonetic phenomenon when VOT in a stop changes as a function of front or back articulation of the following vowel; and (2) this relation can be encoded in phonology of a language when plain, emphatic, or palatalized stops are consistently produced with either short-lag or long-lag VOT.

Qatari Arabic is a convenient case to study a possible effect of tongue position on VOT. VOTs in plain and emphatic / $/$ / in this dialect fall into two distinct categories: plain $/ t /$ is produced with long-lag VOT averaging at $51 \mathrm{~ms}$; emphatic /t/ is produced with short-lag VOT averaging at $14 \mathrm{~ms}$. When emphasis spread changes emphaticness of the plain stop, it may also reduce its VOT. Whether this change, if at all, is gradient or categorical, is an empirical question.

The aim of this study is to investigate whether VOT of syllable initial plain /t/ in CVC syllables is affected by leftward emphasis spreads triggered by syllable final emphatic obstruent. To accomplish this goal, a corpus of Arabic syllables with plain and emphatic consonants was collected and analyzed acoustically. The findings of the study might reveal two scenarios. Under the first scenario, leftward emphasis spread may affect all the acoustic properties of the initial plain stop /t/. Hence, /t/ will become more emphatic in the emphatic environment, which may include production of shorter VOT similar to short-lag VOT of emphatic /ț/. Under the second scenario, emphasis spread may affect only spectral acoustic properties of /t/, but not temporal acoustic properties such as VOT.

2. Method. Sixteen female native speakers of the Qatari dialect participated in this study. All participants were students of Qatar University. Their age ranged between 20 and 25 years old. The participants were not informed about the aim of the experiment. None of them reported speech or hearing disorders. They received a bonus point for participation in one of the registered classes.

The materials included CVC syllables (non-words) with plain and emphatic initial target stops /t/ and /ț/ and final plain and emphatic obstruents /t, s, ð, ț, ș, ð. . Four types of syllable frames were used: 1) /taC/ syllables with initial plain /t/ and final non-emphatic /t/, /s/, and /ð/;

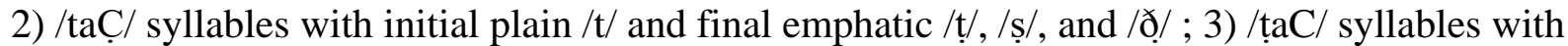
initial emphatic /ț/ and final plain /t/, /s/, and /ð/; 4) /țaC̣/ syllables with initial emphatic stop /ț/ 
and final emphatic /ț/, /ș/, and /ð̣/ . All syllable frames were pronounced with long vowel / a:/ and short vowel /a/.

The vowel and stop VOT boundaries were set manually in Praat (Boersma \& Weenink 2018). VOT was measured as an interval between the release point of the stop and the beginning of the vocal fold vibration. Both the waveform and spectrogram were used to identify the beginning of the glottal pulses. Vowel onset was marked at the point where a periodic pattern was clearly identified along the waveform and spectrogram, and vowel offset was marked at the point where the periodic pattern of vibration of the vocal folds stopped. First, second, and third formant frequencies (F1, F2, and F3) were measured at the onset, midpoint and end point of each vowel to evaluate the degree of emphasis spread. The measurements were taken from LPC spectra calculated over a $25 \mathrm{~ms}$ Hamming window. In addition, the emphaticness index was calculated as a difference between F2 and F1 at the same points. The mean spectral centre of gravity (SCG) of stop burst was measured to evaluate the glottal state and degree of emphasis in stop articulation during the release. The full Hamming window was centered over the burst. Figure 1 exemplifies acoustic measurements.

A.

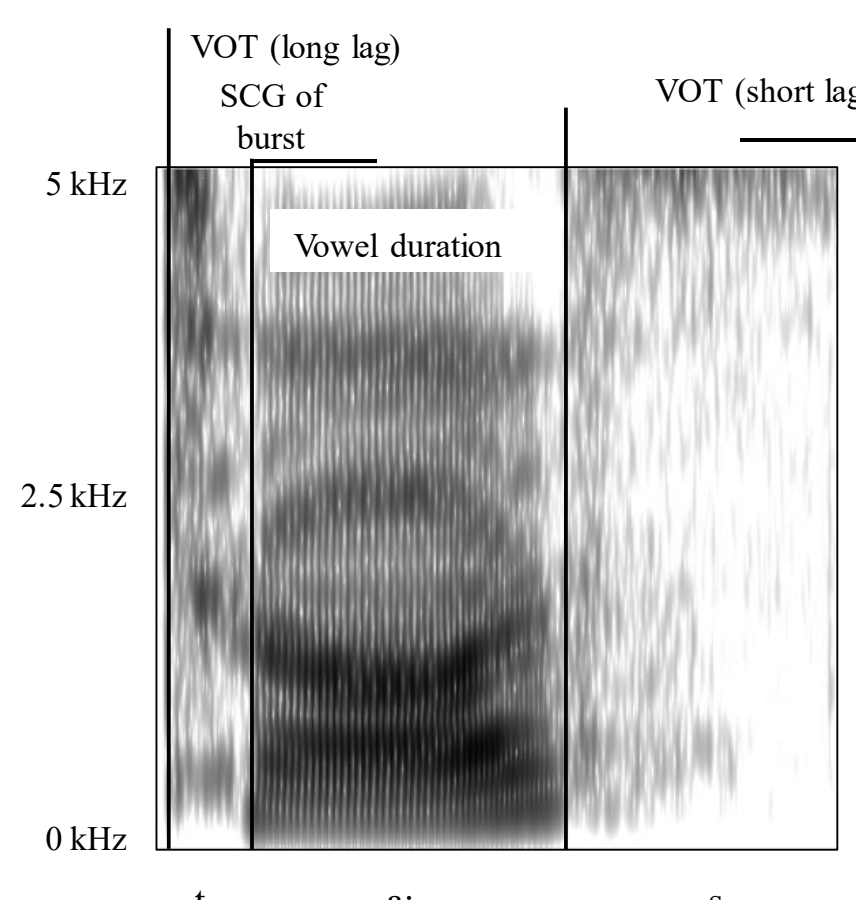

B.

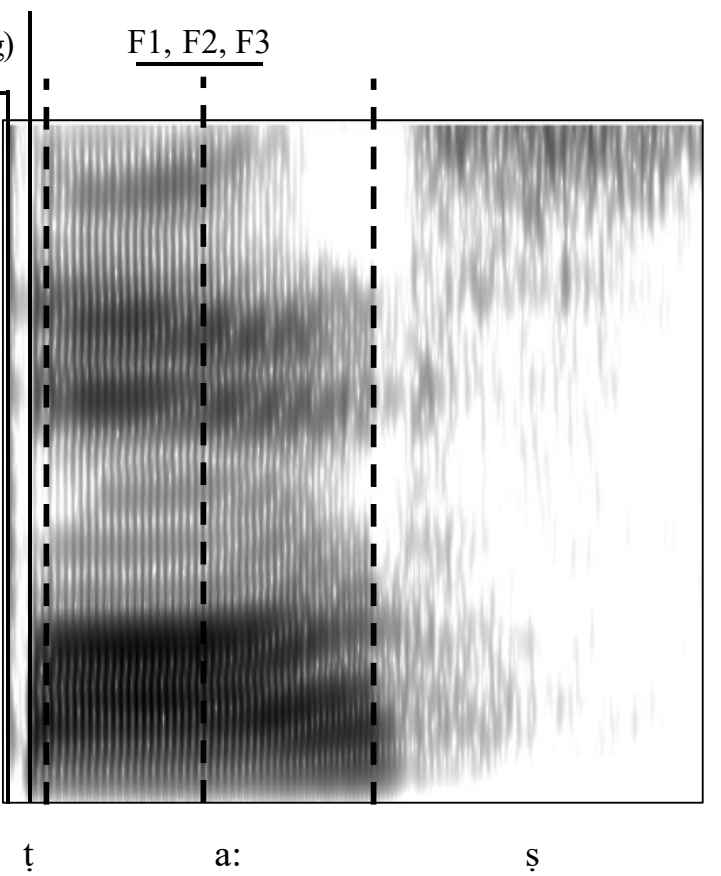

Figure 1. The spectrograms of the syllables (A)/ta:s/ and (B) /ța:ș/ showing acoustic measurements in syllable initial stops and vowels.

The stimuli were presented to the participants in standard Arabic orthography, in which plain / $t /$ and emphatic / $t /$ are distinguished phonemically. The target syllables were recorded in a meaningful carrier sentence Ahmed gaal .... 'Ahmed said ...'. Each target syllable was pronounced two times. The total of 768 syllables ( 24 syllables $* 2$ times $* 16$ participants) were prepared for acoustic analysis. 
3. Results. Analysis of the acoustic cues included several stages. First, we analyzed duration and formant frequencies of the vowel to ensure that speakers differentiated between long and short vowels as they read non-word stimuli. Next, we measured three formant frequencies of the vowels at vowel onset, midpoint, and offset and calculated emphaticness index (F2-F1) to ensure that emphasis spread to the left from the syllable final consonant through the vowel. Then, we measured SCG of burst of the syllable initial target stop to ensure that it was affected by emphasis spread. Finally, we measured VOT of the syllable initial target stop to evaluate to what extent it was affected by emphasis spread.

3.1. VOWEL QUALITY AND DURATION. Vowel quality was evaluated in the unambiguous plain context, when it was flanked by two plain consonants, and in the unambiguous emphatic context, when it was flanked by two emphatic consonants. A repeated measures Analysis of Variance (ANOVA) with Vowel length and Emphasis as independent variables was used for each of the three acoustic cues (vowel duration, F1, and F2 at vowel midpoint) in /t__C/ and /t._c C/ syllable frames.

For vowel duration, significant main effects of Vowel length $(F(1,15)=113.78, p<.0001)$ and Emphasis $(F(1,15)=6.44, p<.05)$ were found. Duration of long /a:/ averaged at $202 \mathrm{~ms}$; duration of short /a/ averaged at $128 \mathrm{~ms}$. Vowels in the emphatic environment were $6 \mathrm{~mm}$ longer than in the plain environment. Figure 2 illustrates the results.

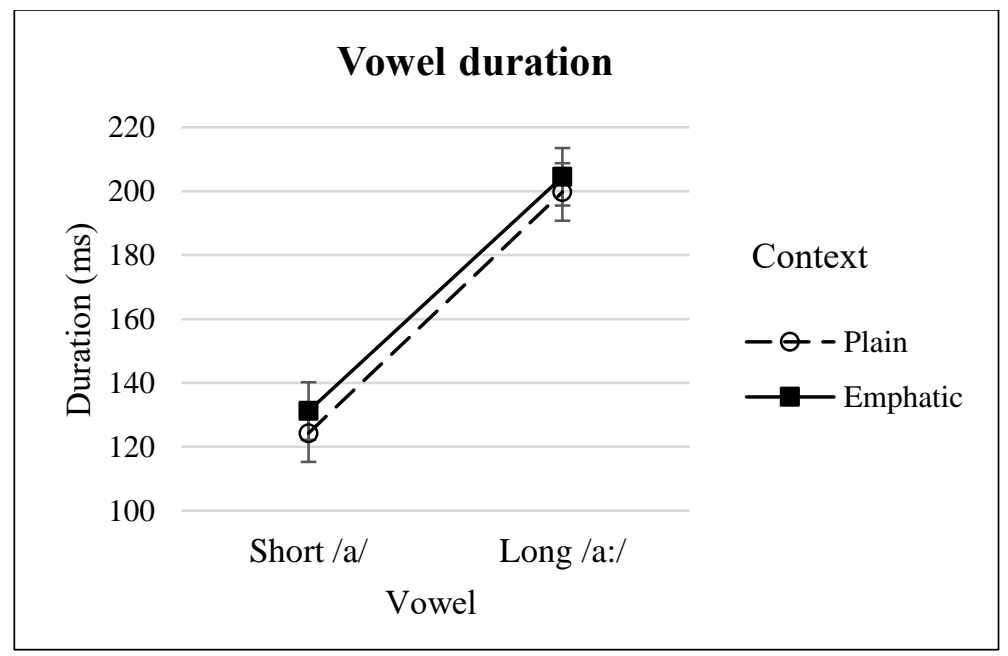

Figure 2. Effects of vowel length and context on vowel duration of short /a/ and long /a:/.

For the first formant frequency (F1), both main effects of Vowel length $(F(1,15)=24.02, p$ $<.0001)$ and Emphasis $(F(1,15)=11.93, p<.01)$ were significant. Short $/ a /$ had lower F1 than long /a:/. F1 was higher in the emphatic context, but the significant interaction $(F(1,15)=21.99$, $p<.0001)$ revealed that $53 \mathrm{~Hz}$ difference between the plain and emphatic conditions was found only in short /a/.

For the second formant frequency (F2), the main effects of Vowel length $(F(1,15)=45.68$, $p<.0001)$ and Emphasis $(F(1,15)=65.06, p<.01)$ were also significant, and the factors did not interact $(p>0.5)$. Short /a/ had higher F2 than long /a:/, and F2 was consistently lower in the emphatic context, suggesting the tongue was retracted when the vowel was produced with emphasis. Figure 3 illustrates differences in production of long /a:/ and short /a/ in the plain and emphatic contexts. 


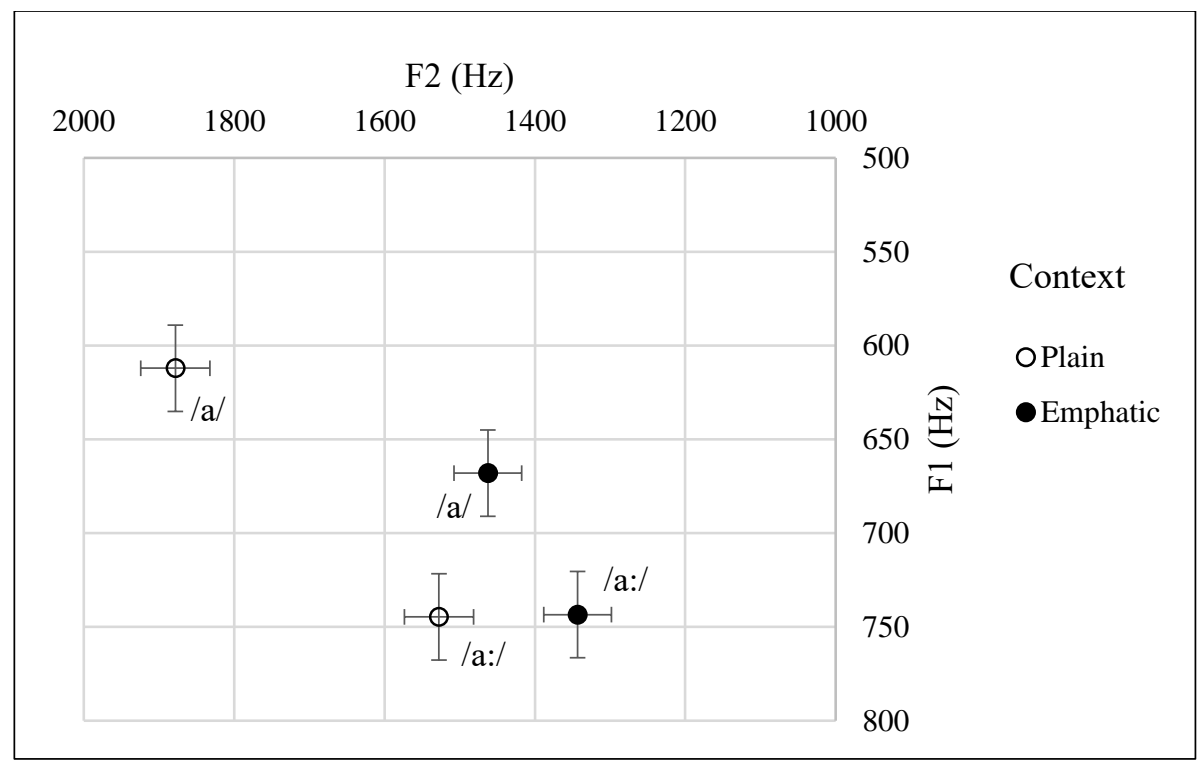

Figure 3. Effects of Vowel length and Emphasis on F1 and F2 of short /a/ and long /a:/.

3.2. EMPHASIS SPREAD: VOWEL FORMANTS. To evaluate the degree of emphasis spread across the syllable, F1, F2 and F3 frequencies were measured at the beginning, middle, and end of the vowel. A repeated measure (ANOVA) was performed with Emphasis, Target stop, and Vowel length as independent variables for each acoustic cue at each of the three locations. Figure 4 summarizes the results.

3.2.1. EMPHASIS. As shown in Figure 4 (right column), the vowels preceding the final emphatic consonant had a higher F1, lower F2, and higher F3 than the vowels preceding the final plain consonant. F1 was significantly higher before emphatic $\mathrm{C}$ at vowel offset $(F(1,15)=15.69, p<$ $.001)$, but it did not reach significance level at vowel midpoint and vowel onset $(p>.05)$. F2 was significantly lower preceding emphatic $C$ throughout the entire vowel at vowel offset $(F(1,15)=$ $50.51, p<.0001)$, vowel midpoint $(F(1,15)=53.21, p<.0001)$, at vowel onset $(F(1,15)=19.10$, $p<.001)$. F3 was significantly higher preceding emphatic $C$ at vowel offset $(F(1,15)=31.04, p$ $<.0001)$, vowel midpoint $(F(1,15)=29.26, p<.0001)$, and at vowel onset after initial plain /t/ $(F(1,15)=4.72, p<.05)$.

3.2.2. TARGET STOP. As shown in Fig. 4 (left column), the vowels following the initial emphatic / $\mathrm{t} / \mathrm{had}$ a higher $\mathrm{F} 1$, lower $\mathrm{F} 2$, and higher F3 than the vowels following the initial plain /t/. F1 was significantly higher following emphatic $/ t /$ at vowel onset $(F(1,15)=20.78, p<.0001)$, vowel midpoint $(F(1,15)=14.94, p<.01)$, but it did not reach significance level at vowel offset $(p$ $=.213)$. F2 was significantly lower following emphatic $/ \mathrm{t} /$ at vowel onset $(F(1,15)=95.55, p$ $<.0001)$, vowel midpoint $(F(1,15)=38.32, p<.0001)$, but it did not reach significance level at vowel offset $(p=.785)$. F3 was significantly higher following emphatic $/ \mathrm{t} /$ at vowel onset $(F(1,15)=4.93, p<.05)$, vowel midpoint $(F(1,15)=12.11, p<.01)$, and vowel offset $(F(1,15)=$ $10.97, p<.01)$.

Significant interactions between Emphasis in the final consonant and initial Target stop in F1, F2, F3 at vowel onset ( $p$ in the range between .006 and .024) and in F2, F3 at vowel offset ( $p$ in the range between .01 and .011 ) revealed that emphasis spread was gradient. The vowel had more emphatic quality closer to the emphatic consonant. 
Target stop
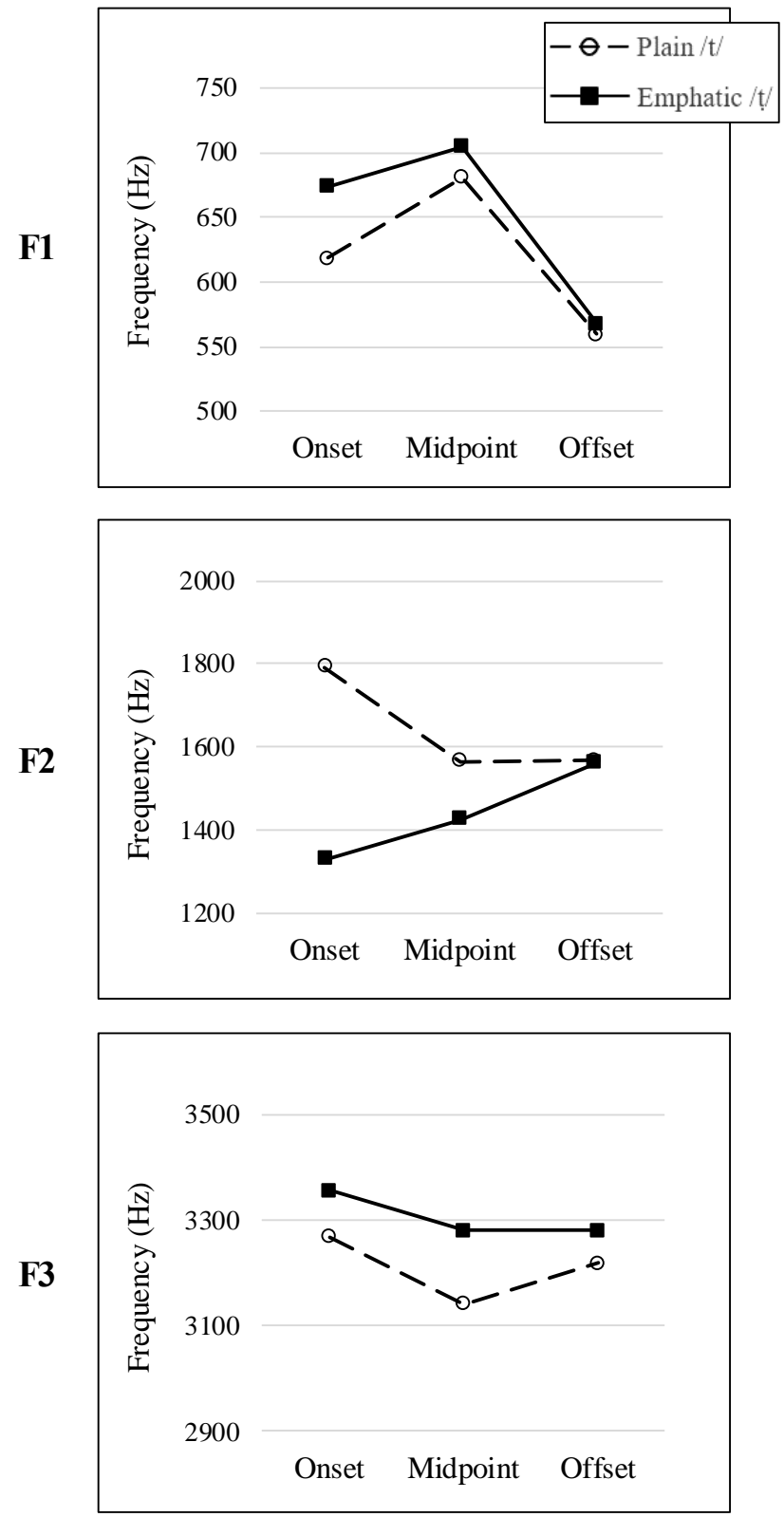

Context
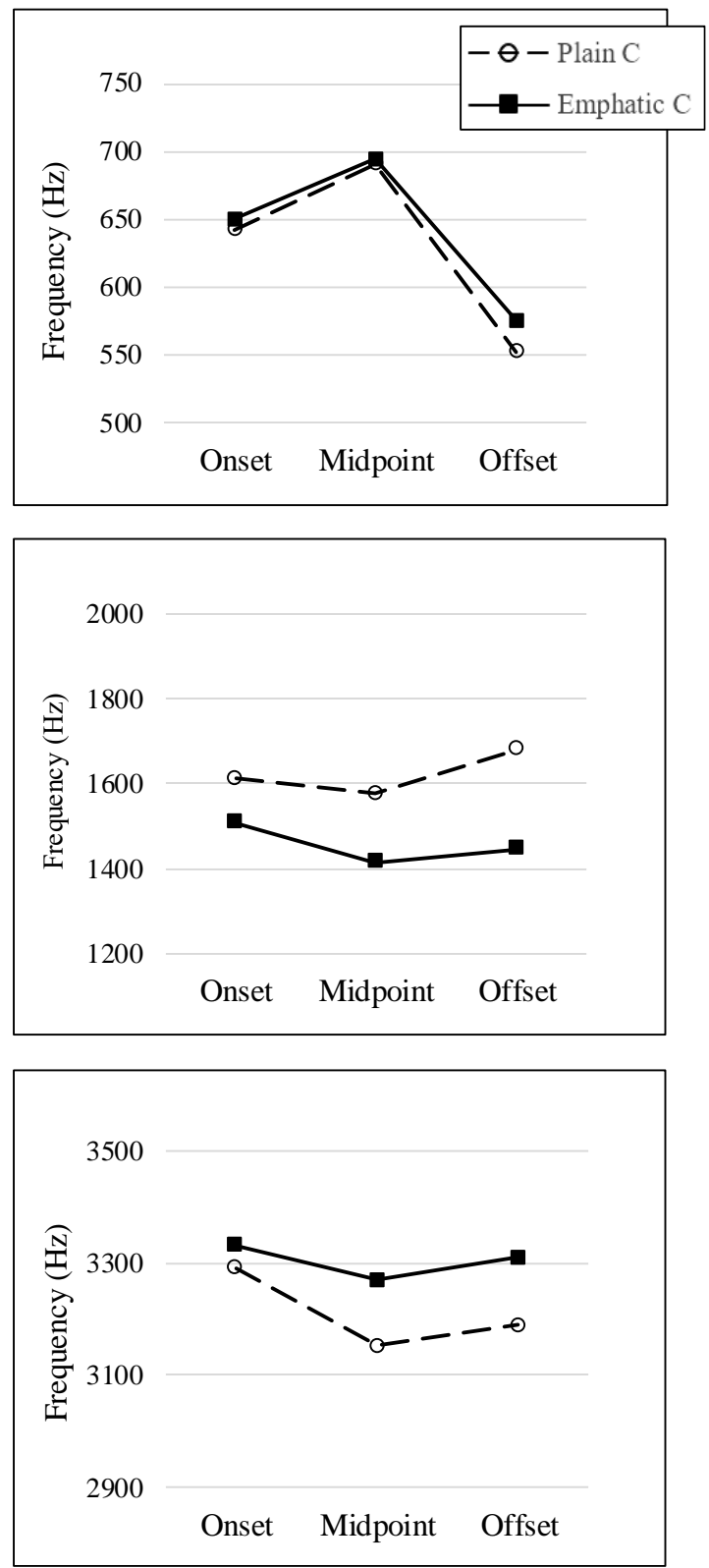

Figure 4. Effects of emphasis in initial (left column) and final (right column) obstruents on F1 (upper row), F2 (middle row), and F3 (lower row) at onset, mid and end points.

3.2.3. VowEL LENGTH. A main effect of vowel length was found for all three formants. Short /a/ had significantly lower F1 ( $F$ values ranging from 15.41 to $19.38, p$ values ranging from .047 to $.0001)$ and higher $\mathrm{F} 2$ ( $F$ values ranging from 4.69 to $35.88, p=.001)$ throughout the entire vowel than long /a:/. Short /a/ had significantly lower F3 than long /a:/ at vowel onset $(F(1,15)=8.84, p$ $<.01)$, but the difference was not significant at vowel midpoint and offset $(p>0.05)$. Significant Vowel length by Emphasis interactions for $\mathrm{F} 1(F(1,15)=12.23, p<.01)$ and $\mathrm{F} 2(F(1,15)=4.66$, $p<.05)$ at vowel midpoint suggested emphasis spread was more prominent in short vowels than in long vowels. This difference may be because the midpoint of the short vowel is closer to the emphatic consonant that triggers this effect than the midpoint of the long vowel. 
3.3. EMPHASIS SPREAD: F2-F1 EMPHATICNESS INDEX. The emphaticness index was calculated as a difference between F2 and F1, following Yeou (1997). Emphasis lowers F2 and raises F1 of a vowel, making values of the two formants closer to one another. Therefore, a smaller F2-F1 difference will indicate an emphatic vowel, whereas a greater F2-F1 difference will indicate a plain vowel. The emphaticness index was evaluated using a factorial repeated measures ANOVA with Vowel length, Target stop, and Context as independent variables at each of the three measurement points. Figure 5 summarizes the results.

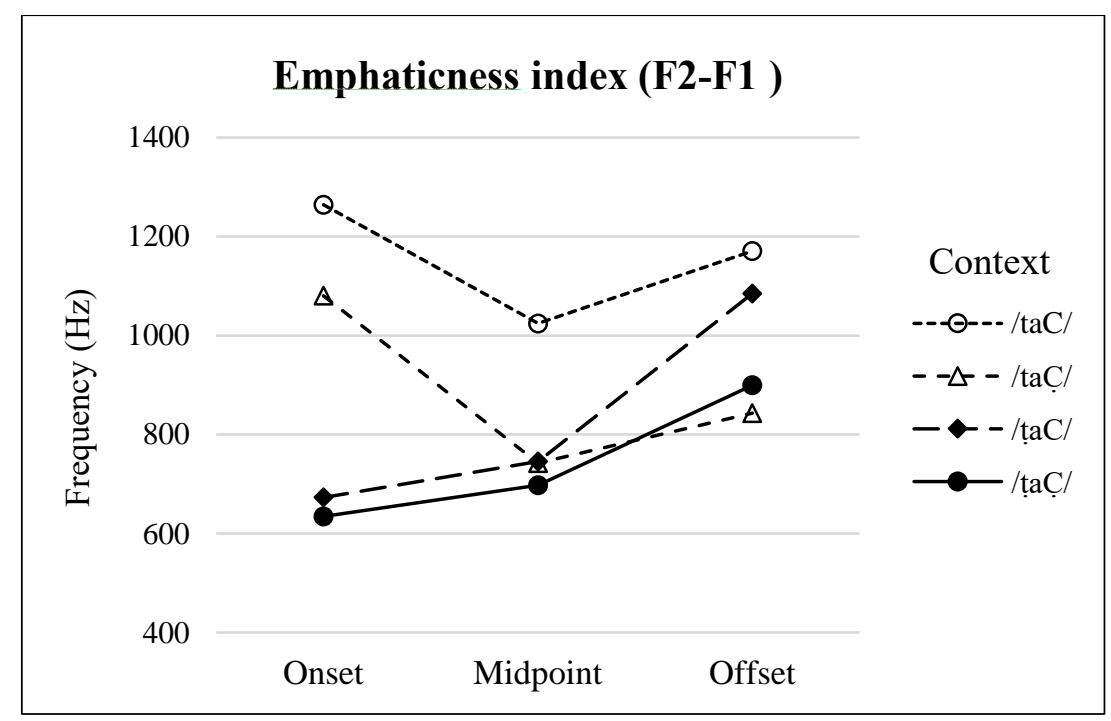

Figure 5. Emphaticness indices (F2-F1) in the four syllable frames at vowel onset, midpoint and offset.

A main effect of Vowel length was obtained at each point ( $F$ values ranging between 12.17 and 54.9, $p$ values ranging between .001 and .0001), indicating that emphasis was more prominent in a short vowel, which was consistent with the previous analysis of raw formant values. Vowel length interacted with Target stop at vowel offset and with Context at vowel onset and midpoint ( $F$ values ranging between 4.86 and 12.15, $p$ values ranging between .044 and .003), indicating that differences between emphatic and plain consonants were more prominent in syllables with a short vowel.

A main effect of Target stop was found at vowel onset $(F(1,15)=94.15, p<.0001)$ and midpoint $(F(1,15)=50.39, p<.0001)$, suggesting the underlying difference between plain $/ \mathrm{t} /$ and emphatic /t / was maintained as far as the middle of the vowel. At vowel offset the effect did not reach significance $(p=.491)$, suggesting some kind of contrast neutralization.

A main effect of Context was obtained at each of the three locations (Onset: $F(1,15)=22.97$, $p<.0001$; Midpoint: $F(1,15)=55.94, p<.0001$; Offset: $F(1,15)=50.47, p<.0001)$, revealing that emphaticness of the syllable final consonant prevailed throughout the entire syllable.

Significant interactions between Target stop and Context were also obtained at each of the three locations ( $F$ values ranging between 7.72 and 19.4, $p$ values ranging between .014 and .001). Subsequent t-tests revealed that changes in emphaticness indices were gradient and varied as a function of emphasis in both initial and final consonants. The index was lower (hence, stronger emphasis) at vowel onset after initial emphatic /t $/(p<.0001)$ in both contexts, the difference between emphatic and plain context being non-significant $(p=.622)$, but 
emphasis varied after initial plain $/ \mathrm{t} /$, with lower index in the emphatic context $(p=.005)$. At vowel midpoint, the emphaticness index was significantly higher $(p<.0001)$ in non-emphatic / t_C/ syllables than in syllable with an initial and/or final emphatic consonant $(p>0.1)$. At vowel offset, the difference in emphaticness was completely neutralized in the emphatic context $(p=0.933)$, but in the plain context indices were significantly higher for plain $/ \mathrm{t} / \mathrm{than}$ for emphatic /t $/(p<.05)$. The indices after the latter were nevertheless not as low as after emphatic / $/ \mathrm{t} /$ in the emphatic context $(p<.0001)$.

3.3.1. EMPHASIS SPREAD: INTERIM SUMMARY. The analysis of the vowel formants revealed that emphasis was spreading from the emphatic consonant through the vowel. This affected articulation of the vowel making it more emphatic. Most noticeable articulatory change in the emphatic context was backing of the vowel. Both leftward and rightward emphasis spread were observed in Qatari Arabic. The vowel had emphatic articulation when it followed a syllable initial or preceded a final emphatic consonant. The results also revealed that emphasis spread was gradient. The strongest effect of emphasis on the vowel was found at vowel midpoint, but the effect of emphasis was reduced at vowel edges.

3.4. EMPHASIS SPREAD: SCG OF BURST. Next, we examined how spectral characteristics of an initial stop are affected by emphasis spread from the final emphatic consonant. A repeated measure (ANOVA) was performed with Emphasis, Target stop, and Vowel length as independent variables for the spectral mean of stop burst. Figure 6 summarizes the results.

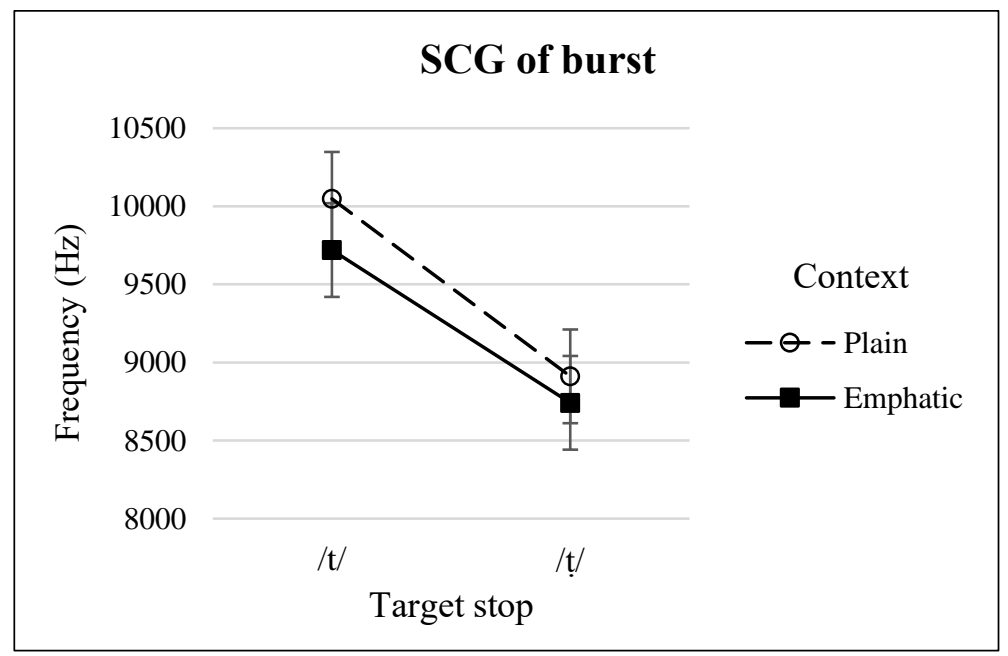

Figure 6. Effect of emphasis spread on mean burst frequency in plain /t/ and emphatic /ț/.

Main effects of Emphasis $(F(1,15)=5.0, p<.05)$, Target stop $(F(1,15)=10.42, p<.01)$, and Vowel length $(F(1,15)=8.09, p<.01)$ were obtained. The results show that the effect of emphasis spread on the initial consonant was gradient. As expected, plain /t/ had higher mean burst frequency $(M=9883 \mathrm{~Hz}, S E=305)$ than emphatic $/ t \operatorname{l}(M=8826 \mathrm{~Hz}, S E=442)$ in general. Both stops had higher mean burst frequency in the plain context $(M=9479 \mathrm{~Hz}, S E=341)$ than in the emphatic context $(M=9231 \mathrm{~Hz}, S E=352)$. Burst frequency was higher before short $/ \mathrm{a} /(M=$ $9678 \mathrm{~Hz}, S E=331)$ than before long /a:/ $(M=9032 \mathrm{~Hz}, S E=388)$. Crucially, the SCG of burst of plain /t/ was $328 \mathrm{~Hz}$ lower in the emphatic context than in the plain context, suggesting emphasis spread affected spectral characteristics of the target stop. 
3.5. EMPHASIS SPREAD: VOT. Finally, we examined the effect of emphasis spread on VOT in the initial alveolar stop. A repeated measure analysis of variance (ANOVA) was performed with Emphasis, Target stop, and Vowel length as independent variables to evaluate VOT duration. The results are summarized in Figure 7. As expected, a main effect of Target stop was highly significant $(F(1,15)=131.62, p<0.0001)$. Plain $/ t /$ was produced with long-lag VOT averaging at $53 \mathrm{~ms}$, whereas emphatic /ț/ was produced with short-lag VOT averaging at $16 \mathrm{~ms}$. However, the analysis did not reveal significant main effects of Context on VOT $(F<1)$ or Vowel length $(F<1)$. Crucially, VOT of plain /t/ was not reduced in the emphatic context, nor did it change as a function of length of the following vowel.

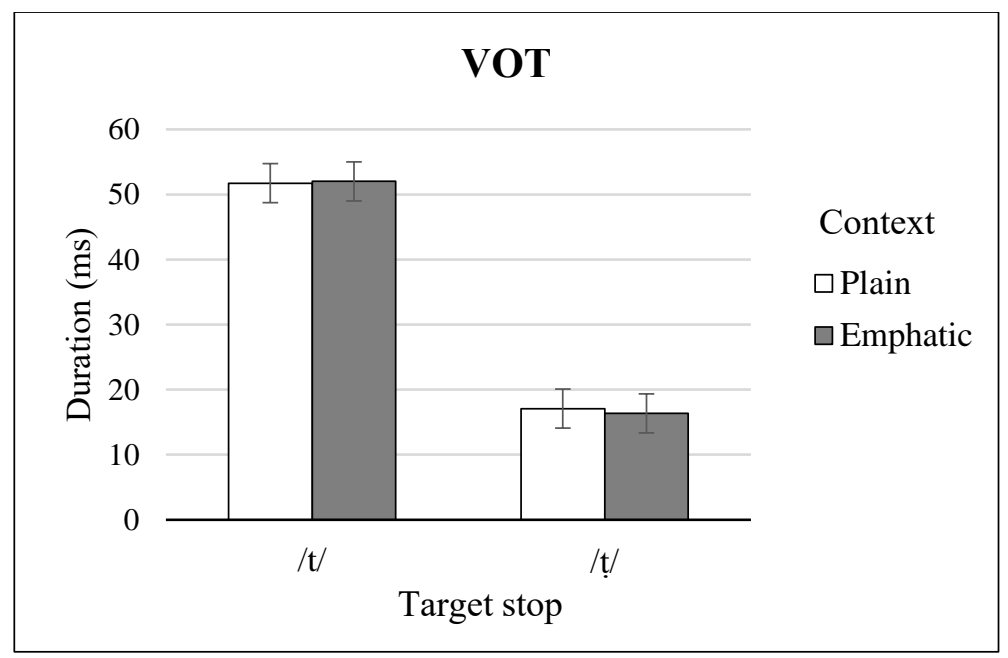

Figure 7. Effect of emphasis spread on VOT in plain /t/ and emphatic /ț/.

4. Discussion and conclusion. The goal of this study was to investigate whether syllable initial plain stop / $t /$ is affected by leftward emphasis spread in Qatari Arabic and whether this affects stop VOT. Specifically, we asked if VOT becomes shorter, and thus more similar to VOT of emphatic /t $/$, when plain $/ t /$ is produced in the emphatic context. The data were collected from 16 native speakers of Qatari Arabic, who read non-word CVC syllables with plain and emphatic initial and final consonants. In addition to answering the main question, we investigated to what extent emphasis spread affects neighboring segments within a syllable. Acoustic analysis of segments affected by emphasis spread focused on F1-F3 of the vowel and on spectral mean of burst in initial stops.

Some results of the study replicated results of the previous studies of emphasis spread (e.g. Jongman et al. 2011, Zawaydeh \& de Jong 2002), and some were new. As it was previously reported in the literature (Watson 1999), Qatari Arabic showed both leftward and rightward emphasis spread, which affected the entire adjacent vowel. The results showed that F2 of the vowel produced in the emphatic context was considerably lowered, which was consistent with results reported earlier in (Jongman et al. 2011, Zawaydeh 1999, Zawaydeh \& de Jong 2002, Yeou 1997). In addition, the results showed that F1 and F3 were raised in the emphatic context. These findings in part replicate the results in (Jongman et al. 2011), who also found significant raising of these formants in Jordanian Arabic arguing for uvularization of emphatic sounds in this dialect. However, the results of the current study show that raising of F1 in Qatari Arabic was not as robust as in Jordanian Arabic. It was most prominent immediately after the emphatic stop, but in the portion of the vowel next to the final emphatic consonant this difference was 
small. Weaker effect of emphasis on F1 in Qatari Arabic was also reported in (Kulikov 2018), suggesting emphasis in this dialect is mainly realized as uvularization, i.e. tongue movement to the back of the vocal tract toward the uvula, rather than pharyngealization, which should have caused F3 lowering and more prominent F1 raising (Jongman et al. 2011).

The results showed that both long and short vowels were affected by emphasis spread, but the magnitude of the effect was different for short /a/ and long /a:/ The effect size of emphasis was greater on the short vowel: it showed greater F2 lowering and considerable F1 raising than the long vowel, where F1 did not raise significantly and F2 had smaller magnitude of lowering. However, it does not mean that long vowels are more resilient to emphasis spread. Smaller degree of emphasis spread in long vowels may be a mere consequence of its more back articulation in the plain context. The tongue retraction simply does not have to be substantial because the long vowel already has central/back quality. The short vowel, in contrast, has front articulation in Qatari Arabic and thus, has to be retracted more in the emphatic context when the tongue is aimed to reach the uvular region of the vocal tract.

The results revealed that emphasis spread also influenced spectral characteristics of the initial stops. SCG of burst of plain /t/ was lowered in the emphatic context. These results have not been previously reported in acoustic studies of emphasis, but they are consistent with Jongman et al's (2011) findings that leftward emphasis spread is more prominent in (voiced) stops than in fricatives. Therefore, the influence of an emphatic consonant on burst frequency of the preceding stop was not unexpected.

Finally, our results revealed that VOT in initial plain /t/ stop did not indicate any influence from emphatic context. We found that underlying plain /t/ and emphatic/t $/$ in Qatari Arabic belong to two different VOT categories, replicating the results in (Kulikov 2018): plain /t/ has long-lag VOT, emphatic / $t$ / has short-lag VOT. This contrastive difference between plain / $t /$ and emphatic/ț/ was maintained in both plain context and emphatic context indicating that emphasis spread did not affect temporal acoustic cues in plain stops. Our findings suggest that there is no relationship between the degree of emphasis and VOT when emphasis is not underlying but spreads from another consonant.

Although underlying emphatic/t/ does have substantially shorter VOT, this acoustic property does not appear to be a mandatory requirement of emphatic articulation. In Qatari Arabic, shortlag VOT is a property of phonological emphatic stop /t /, but VOT shortening does not emerge as an automatic aftermath of tongue retraction that ensures emphasis spread in adjacent segments. These results suggest that emphasis may be more resilient to coarticulatory effects than palatalization, which causes both phonetic and phonological changes in stop articulation resulting in VOT lengthening and optional affrication. Yeou (1997) had a similar claim comparing locus equations of emphatic (pharyngealized) and non-emphatic obstruents in Morroccan Arabic. He argued that emphatic coronals are more resistant to coarticulation because they impose high requirement on the tongue body in their articulation. The tongue front and tongue back have to produce two places of articulation in the front and back areas of the vocal tract, leaving no room for additional gestures. Palatalization in coronal stops, in contrast, is produced by the same front part of the tongue as the primary constriction, which may allow for more variation in production of VOT.

The findings of the current study do not support the hypothesis about dynamic relation between vowel frontness/backness and VOT. The relation similar to correlation between 
longer VOT in emphatic /ț/ produced with weaker emphasis and higher F2 in adjacent vowel reported in Khattab et al.'s (2006) was not found in this study. We hypothesized that the opposite process, namely shortening of VOT as a result of F2 lowering, might be found when emphasis spreads onto a plain stop within a syllable. Yet the findings did not support this scenario. We can suggest two explanations to this. First, it is possible that vowel fronting is an aftermath of a categorical sound change. Loss of emphasis in female speech in Jordanian Arabic ultimately results in a larger number of plan realizations of emphatic / $t$ /, which, in turn, triggers front articulation of the vowel. Second, it is also possible that this asymmetry is yet another result of resistance of emphasis to coarticulation discussed above. VOT may be more sensitive to vowel fronting in cases when emphasis is being lost and vowel articulation becomes more front triggering contextual palatalization of a coronal stop. But the opposite process, i.e. more emphatic articulation of the vowel, does not have an effect on VOT. Future research in this area will provide more details to our understanding of the mechanics of this process.

In conclusion, this study investigated the effect of emphasis spread on VOT in non-emphatic (plain) / $t$ / in emphatic context in Qatari Arabic. Although emphasis spread influenced the vowel quality (F1-F3) and spectral mean of the stop, no effect of emphasis was found for VOT.

Emphasis spread in Qatari Arabic seems be a phonetic rather than phonological process as it does not lead to complete transformation of the stop category.

\section{References}

AlDahri, Sulaiman S. 2013. A study for the effect of the emphaticness and language and dialect for voice onset time (VOT) in Modern Standard Arabic (MSA). Signal \& Image Processing: An International Journal 4(2). 11-29. https://doi.org/10.5121/sipij.2013.4202.

AlGryani, Ali. 2014. Emphasis spread in Libyan Arabic. International Journal on Studies in English Language and Literature 2. 30-38.

Boersma, Paul \& David Weenink. 2018. PRAAT: Doing phonetics by computer [Computer program]. Version 6.0.37, retrieved 14 March 2018 from http://www.praat.org/

Davis, Stuart. 1995. Emphasis spread in Arabic and grounded phonology. Linguistic inquiry 26. 465-498.

Feghali, Habaka J. 2008. Gulf Arabic: The dialects of Kuwait, Bahrain, Qatar, UAE, and Oman. Wheaton, MD: Dunwoody Press.

Ghazeli, Salem. 1977. Back consonants and backing coarticulation in Arabic. University of Texas at Austin dissertation.

Jongman, Allard, Wendy Herd, Mohammad Al-Masri, Joan Sereno \& Sonja Combest. 2011. Acoustics and perception of emphasis in Urban Jordanian Arabic. Journal of Phonetics 39. $85-95$.

Khattab, Ghada, Feda Al-Tamimi \& Barry Heselwood. 2006. Acoustic and auditory differences in the /t/-/ț/ opposition in male and female speakers of Jordanian Arabic. In Sami Boudelaa (ed.), Perspectives on Arabic Linguistics XVI. 131-160. Cambridge, UK: John Benjamins. https://doi.org/10.1075/cilt.266.09.

Knyazev, Sergey. 2016. Affricated dental plosives in Russian: Phonological status and perceptual cues as a trigger of sound changes. Linguistica Lettica 24. 138-146.

Kochetov, Alexei. 2006. Testing licensing by cue: A case of Russian palatalized coronals. Phonetica 63. 113-148. https://doi.org/10.1159/000095305. 
Kulikov, Vladimir. 2018. Weighting cues in production of stop voicing and emphasis in Qatari Arabic. Paper presented at the 16th Conference on Laboratory Phonology, Lisbon, Portugal. https://doi.org/10.13140/RG.2.2.22550.50241.

Kulikov, Vladimir. 2019. Laryngeal contrast in Qatari Arabic: Effect of speaking rate on VOT. Phonetica 76. https://doi.org/10.1159/000497277.

Lisker, Leigh \& Arthur S. Abramson. 1964. A cross-language study of voicing in initial stops: acoustical measurements. Word 20. 384-422.

McCarthy, John J. 1994. The phonetics and phonology of Semitic pharyngeals. In Patricia Keating (ed.), Phonological structure and phonetic form: Papers in laboratory phonetics III. 191-233. Cambridge, UK: Cambridge University Press.

Mitleb, Fares M. 2001. Voice onset time of Jordanian Arabic stops. The Journal of the Acoustical Society of America 109(5). 2474.

Nearey, Terrance M. \& Bernard L. Rochet. 1994. Effects of place of articulation and vowel context on VOT production and perception for French and English stops. Journal of the International Phonetic Association 24(1). 1-18.

Ringen, Catherine \& Vladimir Kulikov. 2012. Voicing in Russian stops: Cross-linguistic implications. Journal of Slavic Linguistics 20. 269-286.

Watson, Janet C. 1999. The directionality of emphasis spread in Arabic. Linguistic Inquiry 30(2). 289-300.

Watson, Janet C. 2002. The phonology and morphology of Arabic. New York: Oxford University Press.

Yeni-Komshian, Grace H., Alfonso Caramazza \& Malcolm S. Preston. 1977. A study of voicing in Lebanese Arabic. Journal of Phonetics 5. 35-48.

Yeou, Mohamed. 1997. Locus equations and the degree of coarticulation of Arabic consonants. Phonetica 54. 187-202.

Zawaydeh, Bushra A. 1999. The phonetics and phonology of gutturals in Arabic. Indiana University dissertation.

Zawaydeh, Bushra A. \& Kenneth de Jong. 2002. Uvularization spread in Arabic. Speech Prosody and Timing, Dynamic Aspects of Speech: IULC Working Papers in Linguistics 4. 93-107.

Zawaydeh, Bushra A. \& Kenneth de Jong. 2011. The phonetics of localizing uvularization in Arabic. In Barry Heselwood \& Zeki Hassan (eds.), Instrumental studies in Arabic phonetics. 257-276. Amsterdam: John Benjamins. 